\title{
Mucamas y domésticas - trabajo femenino, justicia y desigualdad (Mar del Plata, Argentina, 1956-1974)*
}

\author{
Inés Pérez** \\ Débora Garazi ${ }^{* * *}$
}

\section{Resumen}

Este artículo se propone como una contribución a la historia del servicio doméstico, a partir de la reconstrucción de algunos de los caminos recorridos por el trabajo doméstico remunerado en la Argentina de las décadas centrales del siglo XX. Observamos la construcción de las categorías de mucama "doméstica" y "de hotel" en la legislación de la época y comparamos los derechos laborales obtenidos por unas y otras trabajadoras. Analizamos luego los usos de la ley por parte de distintos actores, en los que se develan continuas superposiciones entre estas categorías laborales. La historia de la legislación laboral y de sus usos revela que, aún décadas después de la emergencia de regímenes legales específicos, existían canales de comunicación entre la situación de unas y otras trabajadoras, asentados en la cercanía de sus tareas con el trabajo doméstico, un trabajo que las mujeres usualmente realizaban de modo gratuito. Si este período fue testigo de la emergencia de unos senderos que se bifurcaban para mucamas de distinto tipo, fue también un escenario propicio para su confusión y superposición, que tuvo como resultado un complejo sistema de desigualdades en el mundo del trabajo y de la justicia.

Palabras-clave: Servicio Doméstico, Mucamas de Hotel, Trabajo Femenino, Derecho Laboral, Género.

\footnotetext{
* Recebido para publicação em 29 de setembro de 2012, aceito em 13 de maio de 2013.

** Becaria post-doctoral del CONICET, docente de la UNMdP. inesp18@yahoo.com

*** Estudiante avanzada de la Licenciatura y Profesorado en Historia de la UNMdP, becaria del CIN. deboragarazi@gmail.com
} 
Domestic and Hotel "Maids" - Women's Work, Justice and Inequality (Mar Del Plata, Argentina, 1956 to 1974)

\begin{abstract}
This article seeks to contribute to the history of domestic service through the reconstruction of some the paths transited by paid domestic work in Argentina in the central decades of the Twentieth Century. We observe the construction of categories such as "domestic maid" and "hotel maid" in the legislation of this period and we compare the different rights granted to these workers. Later, we study the uses of the law performed by different actors, in which the overlapping of those categories is recurrent. The history of the law and its uses reveals that, even decades after different legal regimes were passed, there were channels of communication between the situations of these workers, based in the closeness of their activities with unpaid domestic work, usually done by women. While this period saw the emergence of different paths for different kinds of "maids", it was also the scenery for their confusion and overlapping; the result was a complex system of inequalities in the world of labor and justice.
\end{abstract}

Key Words: Service, Maids, Women's Work, Labor Rights, Gender. 


\section{Introducción}

El 2 de enero de 1959, Edith comenzó a trabajar en el hotel Ambassade de Mar del Plata, desarrollando tareas de limpieza. Veinte días después, el 22 de enero, la relación laboral había ya finalizado, dando inicio, sin embargo, a un litigio que llegaría a los tribunales laborales de la ciudad. Allí, Edith reclamaría 27.614,10 pesos moneda nacional $(\mathrm{m} / \mathrm{n})$, correspondientes a sueldos no pagados e indemnización por despido, derechos enmarcados en el Convenio Colectivo de Trabajo vigente para la Industria Gastronómica. ${ }^{1}$ Hasta aquí, un conflicto laboral más, no muy distinto de muchos otros característicos de este tiempo.

En Argentina, los Tribunales Laborales fueron creados en 1944, para dirimir los conflictos específicos del mundo del trabajo. Fueron creados mediante el decreto 32.347 , ratificado luego por la ley 12.948 de 1947, como forma de asegurar los derechos laborales que se habían sancionado en las décadas previas, y especialmente desde 1943, a través de la intervención del Poder Judicial en los conflictos de trabajo (Nazar, mimeo). El Tribunal Laboral $\mathrm{n}^{\circ}$. 2, frente al que Edith presentó su demanda, fue creado en 1948. El litigio abierto por esta demanda fue una de las 134 causas que llegaron a sentencia por este tribunal en 1960.

El expediente de Edith, sin embargo, presentaría una peculiaridad. Arturo, el propietario del hotel donde Edith se había desempeñado entre principios y mediados de enero de 1959, argüiría que Edith no había trabajado como "mucama de hotel" sino como empleada de "servicio doméstico". Sostendría, además, que no había sido despedida sino que había sido contratada por un período de emergencia excepcional de 15 días. De hecho, ambos elementos serían aceptados por los jueces del tribunal, dando lugar a una sentencia de acuerdo a la que no sólo Edith no tendría derecho más que a 872,50 pesos $\mathrm{m} / \mathrm{n}$ (26.741,60 pesos menos de lo que había reclamado), sino que, además, correría con las costas del juicio que había iniciado. En ese resultado, en

${ }^{1}$ Expediente $\mathrm{N}^{\circ}$ 989, Tribunal de Trabajo No. 2, Mar del Plata, 1960. 
extremo adverso a los intereses de Edith, el cambio en la categoría laboral tendría un peso considerable.

¿Por qué esta "confusión" era posible? En buena medida, porque las actividades realizadas por mucamas domésticas y de hotel eran las mismas. En ambos casos, además, se trataba de empleos feminizados, en los que la condición femenina de quien los realizaba era parte de su misma definición. La diferencia entre unas y otras trabajadoras no se encontraba en qué cosas hacían sino en dónde las hacían y en la capacidad de los empleadores de obtener una ganancia con ese trabajo: desde 1956, el servicio doméstico se definía legalmente por ser realizado en el hogar del empleador, sin que éste tuviera fines de lucrar con él. ${ }^{2}$ En este sentido, la prueba presentada en el juicio no era concluyente $y$ Arturo finalmente aceptó que Edith se había desempeñado en el hotel, aunque sólo como "doméstica" y por un período excepcional. Los elementos que decidieron el cambio de categoría laboral fueron, sin embargo, otros: por un lado, el texto de un recibo firmado por Edith, de acuerdo al que aceptaba 1.500 pesos en concepto de trece días de trabajo como "doméstica extra". Por otro, el hecho de que no estaba afiliada al sindicato correspondiente a las mucamas de hotel (UTGRA). ${ }^{3}$ Así, el tribunal entendió que, en lugar del sueldo fijo y porcentaje de 90 días, setenta y un días de casa, comida y aguinaldo (que le hubieran correspondido como mucama de hotel), Edith sólo debía cobrar seis días de trabajo: aquellos transcurridos entre el día que firmó aquel recibo y el día en que fue despedida.

\footnotetext{
2 Expediente No 734, Tribunal de Trabajo No. 2, Mar del Plata, 1959.

3 Por otro lado, si hubiera sido contemplada por ese régimen, debiera haber sido resuelta en el Consejo de Trabajo Doméstico de la Provincia. Este organismo administrativo, dependiente del Departamento Provincial del Trabajo, fue creado para resolver los conflictos derivados del servicio doméstico en la provincia de Buenos Aires mediante el Decreto Ley 24.348 en 1957, imitando un organismo de idénticas características dependiente del Ministerio de Trabajo y Seguridad Social de la Nación, creado el año anterior y con competencia en la Capital Federal. Los tribunales de trabajo doméstico son los únicos tribunales creados para resolver los conflictos surgidos de un tipo de actividad laboral particular. Sin embargo, el Consejo de la provincia parece nunca haberse puesto en funcionamiento.
} 
Ahora bien, éste no es un caso aislado. En diversas ocasiones, los empleadores intentaban hacer pasar a empleadas de otro tipo (peonas de limpieza, mucamas de hotel, cocineras para establecimientos comerciales o productivos, etc.) como "domésticas" de manera de reducir el monto de dinero que debían pagar en los juicios laborales. Del mismo modo, muchas veces las empleadas domésticas se presentaban ante los tribunales sosteniendo que, en realidad, se habían desempeñado en otros puestos, para aumentar el reclamo y garantizar la competencia del fuero laboral. El recurso a estos artilugios legales sólo tenía lugar cuando las involucradas eran mujeres trabajadoras que se desempeñaban en actividades socialmente construidas como "no calificadas", con un bajo nivel de sindicalización, y sin tareas claramente delimitadas. ${ }^{4}$ Los fallos de los jueces (incluso de un mismo tribunal), sin embargo, podían dar lugar a soluciones muy disímiles, dependiendo de elementos fortuitos como los señalados en el caso de Edith (el texto del recibo, la no afiliación al sindicato, etc.).

Quizás la pregunta más relevante entonces sea aquella por la explicación de la disparidad entre los derechos de trabajadoras que realizaban actividades similares y cuyas situaciones laborales (el tipo de empleador, el lugar de trabajo, etc.) no siempre eran tan distantes. ¿Cómo se construyó dicha distinción? ¿Cómo se erigieron $y$ se deslindaron categorías como "doméstica" y "mucama de hotel"? ¿Cómo jugó la diferencia de género en la vulneración de los derechos de las trabajadoras? ¿De qué modo estas diferencias muestran las jerarquías existentes entre mujeres en el mundo del trabajo? Partimos de la definición de "género" como una forma primaria de relaciones significantes de poder $y$ como un elemento constitutivo de las relaciones sociales que se articulan con la diferencia sexual. ${ }^{5}$ En particular, en este artículo

\footnotetext{
4 Sobre la relevancia de las relaciones de género en la delimitación de los trabajos considerados como "cualificados", ver Wajcman (2005).

5 Esta definición es casi literalmente la que da Joan Scott (1990 [1986]) en un artículo ya clásico. Sin embargo, hemos introducido una variación que responde a las críticas que más tarde se le hicieran, y que ella misma retomaría en trabajos
} 
observamos los modos en que las relaciones de trabajo se articulan en torno a desigualdades de género, al tiempo que dan lugar a nuevas formas de esa desigualdad.

Desde los clásicos estudios de Edward P. Thompson (2010 [1975]), la historiografía ha mostrado distintos modos en que las normas expresan la cristalización de la costumbre en un orden legal, fruto de un correlato de fuerzas específico que logra legitimidad, y también de un modo históricamente dado de comprender y delimitar aquello sobre lo que se legisla. En las normas -y en los debates que les dieron lugar- pueden rastrearse imágenes que distintos actores construían del servicio doméstico, del trabajo femenino, de los usos habituales y de los estándares de aquello que en cierto momento era considerado "correcto" y "justo". Por otra parte, los usos de la ley develan continuas superposiciones entre lo laboral y lo familiar, así como entre distintas categorías laborales. En ellos pueden rastrearse apelaciones, tanto a las normas como a las costumbres, que dan cuenta de nociones encontradas de justicia, aunque también de supuestos comunes, atravesados por representaciones sobre la feminidad, lo doméstico, y el mundo familiar, que resultan centrales en la definición del trabajo femenino y los derechos de trabajadoras y empleadores.

En este artículo analizamos algunos de los caminos recorridos por el trabajo doméstico remunerado ${ }^{6}$ en la Argentina de las décadas centrales del siglo XX. Analizaremos, primero, la construcción de la categoría "servicio doméstico" en la legislación

posteriores, a partir de la que reevaluaría la relación entre sexo y género. Si en su definición inicial Scott hacía depender el género (definido como lo cultural) del sexo (definido como lo biológico), en lecturas posteriores la misma autora da un peso mucho mayor a lo discursivo en dicha relación (Scott, 1991). En este sentido, proponemos aquí la idea de "articulación" entre las desigualdades de género y la diferencia sexual buscando dar cuenta de la complejidad del vínculo entre ambas categorías.

${ }^{6}$ Hablamos en términos genéricos de "trabajo doméstico remunerado" para poder incluir bajo un mismo concepto diversas actividades que se realizan a cambio de una remuneración pero que suponen la extensión en el mundo público de tareas asociadas al trabajo doméstico no remunerado. 
de la época y los modos en que este trabajo fue deslindado de otros cercanos, generando complejas jerarquías entre trabajadoras que realizaban tareas muy cercanas, en condiciones notablemente desiguales. Para ello, nos detendremos en la sanción de un régimen legal para el servicio doméstico y en su comparación con proyectos legislativos previos que no llegaron a ser sancionados, así como en legislación sobre otros trabajos que fueron separados del "servicio doméstico" en este período. Observaremos también la regulación legal de actividades con las que intencionalmente se ha confundido al servicio doméstico, como la actividad de las mucamas de hotel, a quienes se les reconocían otros derechos.

En un segundo momento, analizaremos los usos de la ley por parte de distintos actores, a partir del análisis de las sentencias judiciales dictadas en la ciudad de Mar del Plata entre 1958 y 1974. ${ }^{7}$ Mar del Plata resulta un espacio particularmente relevante para este análisis. El desarrollo de la ciudad como centro de turismo masivo a mediados del siglo $\mathrm{XX}$, fue acompañado de un importante incremento del número de hoteles y de espacios de alojamiento para turistas. Este sector de servicios supuso una importante oferta de trabajo, aunque en la mayoría de los casos de carácter estacionario, para una gran cantidad de mujeres que encontraron allí una forma de acceso al mercado laboral. La existencia de distintas categorías de alojamientos (hoteles, pensiones, departamentos, habitaciones en casas particulares, etc.) fue uno de los factores que contribuyó a la confusión intencionada entre las categorías de "empleada doméstica" y de "mucama". Muchos de estos establecimientos permanecían cerrados buena parte del año, o requerían escaso personal permanente; otros funcionaban casi exclusivamente gracias al trabajo de sus propios dueños, con escaso personal contratado. Así, numerosas relaciones laborales o contratos de trabajo se extendían tan sólo por unos meses, generando situaciones de confusión o

7 Utilizamos las sentencias de este tribunal gracias a la colaboración de los jueces que actualmente lo componen -la Dra. Slavin, el Dr. Noel y el Dr. Riva- que nos han autorizado para su consulta. El período revisado comienza en 1958 puesto que de ese año son los primeros registros de sentencias disponibles en el tribunal. 
irregularidades que perjudicaban a las trabajadoras y que habilitaban el tipo de prácticas analizadas en este artículo.

Desde los años setenta, el trabajo femenino ha ganado espacio en la historiografía sobre América Latina. Los estudios históricos se han centrado en sectores feminizados, como la industria textil y la de alimentos, y en ocupaciones en el área de servicios -docentes, telefonistas, secretarias, etc.- (James y French, 1997; Lobato, 2007). De la mano de la recuperación de las experiencias de las mujeres en el mundo del trabajo, la preocupación central de estos análisis era reconstruir los caminos por los que se habían delimitado "trabajos apropiados para su sexo" (Hutchison, 2001), destacando el peso, que en distintos casos adquirieron las alianzas entre las elites y los varones trabajadores en la exclusión de las mujeres de ciertas ocupaciones, y evidenciando el lugar de distintos agentes estatales en la domesticación de las mujeres (Weinstein, 1996; Rosemblatt, 2000; Hutchison, 2001; Nari, 2004).

Sin embargo, y a pesar de que en la región ha sido la principal ocupación femenina a lo largo del siglo XX, el trabajo doméstico remunerado, $y$ en particular el servicio doméstico, ha sido relativamente descuidado por las Ciencias Sociales, reproduciendo en el campo académico la invisibilidad que lo caracteriza en términos sociales (Olcott, 2011; Blofield, 2009). A pesar de los recientes esfuerzos en este sentido (Hutchison, 2011; Pite, 2011; Blum, 2011; Vázquez Lorda, 2010; Allemandi, 2009), aún queda pendiente una lectura histórica de las transformaciones en el trabajo doméstico remunerado. Este artículo se propone como una contribución a ese creciente campo, a partir de la reconstrucción de las diferenciaciones que se establecieron entre algunas de sus modalidades, cristalizadas en diferentes regímenes legales y, consecuentemente, en desiguales derechos laborales.

\section{El trabajo doméstico remunerado y la ley}

De acuerdo al diccionario de la Real Academia Española, existen dos acepciones del término "mucama": la primera, hace 
alusión a la "persona empleada en el servicio doméstico"; la segunda, en cambio, refiere a quien, en hoteles y hospitales, es la "encargada de la limpieza". Esta ambigüedad, presente en los usos habituales del término, era intencionalmente explotada en el marco de los juicios laborales en las décadas centrales del siglo. En cualquier caso, la posibilidad de confundir la doble acepción de dicha palabra (utilizada como categoría laboral) radica en que tanto las mucamas de hotel como las domésticas eran mujeres y realizaban las mismas tareas: en uno y otro ámbito, eran las encargadas de la limpieza, a quienes se les pagaba una remuneración por realizar ese trabajo.

En Argentina, las tareas de limpieza, incluso las de las "mucamas", no se encuentran bajo un único régimen legal. La categoría profesional depende tanto de las tareas realizadas como del lugar en el que se realizan. En este sentido, las mucamas de hotel tempranamente fueron incluidas bajo la reglamentación de los trabajadores hoteleros. Para 1955, se encontraban, además, bajo la órbita de los trabajadores gastronómicos. ${ }^{8}$ En cambio, y a pesar de los numerosos proyectos que se presentaron desde principios de siglo, el servicio doméstico careció de un régimen legal específico hasta la sanción del Decreto-Ley 326 en $1956 .{ }^{9}$

8 El 2 de agosto de 1948 se constituyó la Federación Obrera Argentina de la Industria Hotelera (FOAIH) la que obtuvo la personalidad gremial, a través de la Resolución No 49/49 de la Secretaría de Trabajo y Previsión de la Nación. Esta Federación agrupó a todos los gremios de las ramas hotelera y gastronómica que se habían constituido en todo el territorio nacional a lo largo de más de 40 años, incluyendo a las mucamas. Posteriormente, el 25 de agosto de 1955, la FOAIH, se transformó en un único sindicato denominado "Unión de Trabajadores Gastronómicos de la República Argentina (UTGRA) (Resolución № 160/55 del Ministerio de Trabajo y Previsión de la Nación.

9 Si bien existieron diversos proyectos para la regulación legal de este sector desde comienzos de siglo, sólo en 1955 uno de ellos alcanzaría media sanción legislativa, proceso detenido por la llamada "Revolución Libertadora" (Tiziani, 2013). Se han establecido distintas etapas para caracterizar los modos en que la legislación argentina reguló el servicio doméstico a lo largo de la primera mitad del siglo XX. En un primer momento, las leyes obreras no se referían al servicio doméstico, salvo para excluirlo. En un segundo período, se sancionaron diversas leyes que excluyeron a algunos trabajadores de la categoría de servicio 
Este Decreto-Ley, que reguló el servicio doméstico en el país hasta principios de 2013, fue particularmente duro en relación a los derechos laborales de las trabajadoras domésticas. ${ }^{10}$ Por una parte, las protecciones que otorgaba eran más limitadas que las garantizadas contemporáneamente a trabajadores de otros sectores -que habían sido extendidas considerablemente en las décadas previas-. Por otra, establecía condiciones restrictivas para la demarcación de quiénes podían ampararse bajo dicho régimen, limitando aún más la protección a las trabajadoras domésticas.

La sanción de un régimen jurídico para el servicio doméstico es un indicio de un cambio en la sensibilidad social en torno de los límites entre el mundo familiar y el laboral, y, en particular, entre el trabajo doméstico remunerado y no remunerado (Zelizer, 2009). El Decreto-Ley 326 de 1956 explícitamente excluyó del empleo doméstico a las personas emparentadas con el empleador. De este modo, ofrecía una respuesta que buscaba ser homogénea frente a una multiplicidad de situaciones ambiguas que sólo recientemente habían comenzado a ser percibidas como problemáticas. Desde mediados de los años treinta y durante la década de los 40, en diversas ocasiones los tribunales se enfrentaron a la necesidad de delimitar en qué casos correspondía una remuneración a cambio de trabajo doméstico cuando existía una relación "afectiva" entre las partes. Los concubinos no casados, los amigos corresidentes y los criados, es decir, niños y -sobre todo- niñas que no eran hijas de aquellos para quienes trabajaban pero que habían vivido con ellos desde edades muy tempranas, eran casos confusos frente a los que, en las décadas previas a la sanción del Decreto 326/56, se había intentado fijar un criterio único mediante fallos que sentaran jurisprudencia (Grinberg, 1952).

doméstico. El mensaje enviado por el Poder Ejecutivo Nacional a la Cámara de Senadores el 18 de diciembre de 1946 iniciaría una tercera etapa, caracterizada por atribuir nuevos derechos al servicio doméstico (Grinberg, 1952; Rojas, 1956; Fescina, 1956).

${ }^{10}$ Si bien el Decreto/ Ley hace referencia a "trabajadores" aquí hablaremos de trabajadoras puesto que ya al momento de la redacción de este decreto, el servicio doméstico era una ocupación eminentemente femenina. 
La década de los años 40, por otra parte, fue el escenario de distintas escisiones dentro del servicio doméstico, que implicaron su redefinición. Ocupaciones que antes estaban bajo ese rótulo -como las de los choferes particulares, los limpiadores de salas de espectáculos, oficinas y casas particulares, o los encargados de casas de renta- ganaron un estatus independiente, garantizado por su vínculo, ya con saberes especializados, ya con el trabajo considerado "productivo". En términos generales, dicha redefinición implicó la separación de ocupaciones identificadas como "masculinas" respecto del "servicio doméstico", lo que contribuyó a su feminización y a su identificación como un trabajo no cualificado (Sarti, 2006; Steedman, 2009). ${ }^{11}$

Este proceso, sin embargo, puede rastrearse desde fines del siglo XIX. Como ha mostrado Cecilia Allemandi (2009), entre 1887 y 1914 la participación de los varones en el "servicio doméstico" disminuyó notablemente: si en 1887 representaban casi el 43\% de los trabajadores del sector, para 1914, esa proporción había disminuido a poco más del 10\%. Ese proceso se acentuaría en las décadas siguientes. Sin embargo, es difícil rastrear esos números en los instrumentos que el Estado utilizó para cuantificar a estos trabajadores y trabajadoras, puesto que los registros que proporcionan no resultan homologables a lo largo del tiempo e implican, en todos los casos, un sub-registro de este tipo de trabajadores. ${ }^{12}$ Un año antes de la sanción del Decreto-Ley 326, en 1956, se estimaba que 350.000 personas se desempeñaban en el servicio doméstico (Fescina, 1956), proporción que para 1964,

${ }^{11}$ Diario de Sesiones, Cámara de Diputados de la Nación, 27 y 28 de Septiembre de 1946, pp. 738-750; Diario de Sesiones, Cámara de Senadores de la Nación, 30 de Septiembre de 1946, pp. 746-749; Diario de Sesiones, Cámara de Diputados de la Nación, 21 de Marzo de 1947, pp. 1-20; Diario de Sesiones, Cámara de Senadores de la Nación, 18 de abril de 1947, pp. 822-826.

${ }^{12}$ Ver III Censo General de Población, Dirección Nacional de Estadística y Censos, 1914; IV Censo General de Población, Dirección Nacional de Estadística y Censos, 1947; Censo Nacional de Población de 1960, Instituto Nacional de Estadística y Censos, 1960. 
alcanzaría el $20.7 \%$ de las mujeres ocupadas en la ciudad de Buenos Aires, siendo la ocupación que más mujeres nucleaba. ${ }^{13}$

Para mediados de los cincuenta, sin embargo, la definición del "servicio doméstico" no era unívoca (Tizziani, 2012). La sanción del Decreto-Ley 326/56 congeló (o, al menos intentó congelar) una definición de dicha actividad, que implicaba su realización en el espacio del hogar de los empleadores, para su familia, y el hecho de que ellos no se beneficiaran económicamente de ese trabajo (de manera directa). Finalmente, en 1974 se sancionó la Ley de Contrato de Trabajo, en la que, nuevamente, las empleadas domésticas (junto a los peones rurales) serían exceptuadas de las regulaciones aplicables al conjunto de los trabajadores. Dicha ley confirmaría la definición del "servicio doméstico" como una actividad distinta de otras realizadas en el mercado de trabajo. En efecto, durante todo este período, el servicio doméstico sería considerado como una ocupación con una naturaleza particular, que requería de un estatuto y de un orden legal especial, debido a la relación establecida con las empleadas en el ámbito de la intimidad de la familia de los empleadores.

A pesar de los intentos por cristalizar la separación entre dichos espacios -visible en el orden de las normas-, las prácticas dieron lugar a continuas superposiciones, rastreables en los usos de la ley de distintos actores. Resulta interesante observar cómo, en el marco de juicios laborales como el reseñado al inicio de este artículo, los empleadores buscaban hacer pasar a mujeres empleadas en otros puestos (como el de mucama de hotel) como "empleadas domésticas" para disminuir los montos reclamados. Este tipo de artilugio no se observaba en casos de trabajadores varones. Incluso si el trabajador realizaba las mismas tareas que una empleada doméstica en una actividad que hasta pocos años

\footnotetext{
${ }^{13}$ Estos datos fueron tomados de Encuestas de empleo y desempleo, Buenos Aires, julio de 1963 y abril de 1964, Instituto Nacional de Estadística y Censos, Buenos Aires, 1964. Tomamos estos datos porque, al no ser posible desagregar los datos del servicio doméstico del Censo Nacional de Población de 1960, éstos resultan los más cercanos temporal y geográficamente a los datos que se busca contextualizar. No se disponen de datos para la ciudad de Mar del Plata.
} 
atrás había estado regulada como "servicio doméstico" (como un peón de limpieza o un encargado de edificio de departamentos, por ejemplo), en ningún caso se lo asimilaba a un trabajador del "servicio doméstico".

Tanto el hecho de que las tareas realizadas por una mucama de hotel y una doméstica fueran las mismas, como la condición femenina de quien las realizaba, habilitaban situaciones difíciles de catalogar para los jueces, y condiciones laborales difíciles de probar para las trabajadoras. La posibilidad de confundir estas actividades redundaba en notables diferencias en la posibilidad de efectivizar los derechos laborales de las trabajadoras, que se asentaban en la existencia de jerarquías dentro del mundo de las mujeres que se desempeñaban en trabajos de limpieza. Dicha jerarquía estaba construida en torno de criterios androcéntricos: el trabajo de las mucamas de hotel garantizaba mayores derechos en tanto se desarrollaba en el espacio público y permitía al empleador la obtención directa de beneficios económicos. ${ }^{14}$

Mientras las mucamas de hotel tenían derecho a indemnización por despido aún si eran temporarias (es decir, si su contrato de trabajo no se extendía por más de 3 meses al año), las domésticas sólo podían reclamar indemnización si tenían al menos tres meses de antigüedad en el puesto. Las mucamas de hotel tenían derecho a indemnización incluso en el caso de que, habiendo trabajado una temporada, no fueran recontratadas el siguiente verano. Por otro lado, el monto de dicha indemnización era sustancialmente menor en el caso de las empleadas domésticas: mientras las mucamas de hotel tenían derecho a cobrar un porcentaje del sueldo de la temporada en la que fueran

\footnotetext{
${ }^{14}$ Es pertinente señalar que la indicación presente en la ley, de acuerdo a la cual los empleadores no se benefician económicamente del servicio doméstico que se realiza en sus hogares, parte del supuesto de que el trabajo doméstico (remunerado o no) no tiene o produce riqueza. Dicho supuesto responde a un paradigma androcéntrico, en el que "trabajo" sólo es aquel que se identifica con el que tradicionalmente han realizado los varones. Sobre las discusiones en torno del concepto de "trabajo" desde una perspectiva de género, ver Cristina Borderías, Cristina Carrasco y Carmen Alemany (1994).
} 
despedidas (incluso del tiempo no trabajado), una suerte de garantía para los trabajadores estacionales, además de que cada temporada completa trabajada se consideraba como un período anual de servicios, las domésticas sólo podían reclamar medio mes de sueldo por cada año (completo) de servicio. El contraste más fuerte, sin embargo, se encontraba en otro elemento: el laudo. ${ }^{15}$

El 4 de septiembre de 1945 la Secretaría de Trabajo y Previsión sancionó el derecho al laudo (un porcentaje de la ganancia de los establecimientos donde se desempeñaran) para trabajadores gastronómicos de todo el país, prohibiendo, al mismo tiempo, las propinas. El argumento principal para la sanción de dicha medida era que la propina, como medio de remuneración del trabajo de los empleados de hoteles, restaurantes, bares y establecimientos similares, impedía que el trabajador contara con recursos fijos y exigibles, ya que constituía una forma irregular de pago, dependiente de la exclusiva voluntad de los clientes. Se estableció, entonces, que los trabajadores tendrían derecho, además de la remuneración fija, a una comisión individual proporcional al valor de los servicios prestados, que debía ser abonada por los clientes. Así, las mucamas de hotel, al igual que otros trabajadores como conserjes, mozos, elevadoristas o telefonistas, entre otros, se verían beneficiados con esta nueva forma de remuneración ${ }^{16}$.

En cualquier caso, tanto para empleadas como (y especialmente) para empleadores la "confusión" entre las categorías de mucamas aquí analizadas podía ser sumamente beneficiosa. Como adelantamos, dicha confusión era favorecida por situaciones laborales particulares, pero da cuenta de modos

\footnotetext{
${ }^{15}$ La legislación aplicable a las mucamas domésticas es el Decreto de Ley 326/56. La legislación del trabajo de las mucamas de hotel fue tomada de Devali (1967).

${ }^{16}$ La ley 12.921, ratificaba el decreto 4148/46, el cual declaró obligatorio el laudo dictado por la Secretaría de Trabajo y Previsión el año anterior (Krotoschin, E. y Ratti, J., 1967). En el período que abarca el presente artículo el "laudo gastronómico" -como se lo denomina comúnmente- establecido por el decreto mencionado, estuvo vigente. Recién en el año 1980 fue expresamente derogado por el decreto-ley 22310.
} 
específicos de representar el trabajo de limpieza como cercano a (y entonces confundible con) el trabajo doméstico - tanto remunerado como no remunerado. En el próximo apartado exploraremos las condiciones que habilitaron la emergencia de estas estrategias -y los argumentos en que se basaron- frente a la ley.

\section{Artilugios legales: trabajo doméstico remunerado y usos de la ley}

El caso de Edith, mencionado al inicio del artículo, no fue único. Como señalamos, las sentencias judiciales muestran una operatoria recurrente en la que los empleadores cuestionaban la clasificación de la demandante como "mucama de hotel", buscando presentarlas como empleadas domésticas. A pesar de que entre 1958 y 1974, los años analizados en este artículo, la composición del tribunal varió muy poco (al menos un juez fue siempre el mismo), las sentencias en los casos en los que se apelaba a esta estrategia no siempre tuvieron el mismo sentido ni siguieron las mismas lógicas.

De los once casos en los que encontramos esta estrategia, sólo en uno se accedió íntegramente al reclamo de la empleada, en cuatro se le reconoció parcialmente, mientras que en seis se desestimaron sus demandas por completo. ¿Qué criterios se tuvieron en cuenta para considerar las demandas de las trabajadoras? El primer aspecto considerado era la existencia de una relación laboral entre la demandante y el demandado. En caso de que ésta fuera probada, se evaluaba la categoría laboral de la trabajadora. En la Justicia Laboral, en caso de duda, correspondía a los empleados comprobar el vínculo laboral, lo que se hacía a partir de la declaración de testigos. Muchas veces, quienes podían testificar sobre la existencia de dicha relación eran personas que mantenían algún tipo de vínculo (laboral, familiar o de amistad) con el empleador, lo que daba a su testimonio un sesgo en contra de los intereses de la trabajadora. A su vez, la similitud entre las tareas realizadas por una mucama de hotel y una empleada doméstica hacía que para ciertos testigos (por 
ejemplo, un vecino) fuera difícil determinar cuál era la relación de la accionante con la parte demandada.

Un dato no menor es que estas relaciones laborales difíciles de catalogar se dieron en el marco de espacios de trabajo que no estaban claramente delimitados, lo que acentuaba sus continuidades con el trabajo doméstico (remunerado y no remunerado). La superposición de categorías laborales era posible cuando la trabajadora se desempeñaba en un establecimiento pequeño, manejado por sus propios dueños y sostenido, en buena medida, gracias al trabajo del conjunto de la familia del empleador. El auge del turismo de masas durante el período analizado (en especial en las décadas de 1960 y 1970) habilitó la emergencia de numerosos establecimientos de esas características, como parte de las estrategias de los habitantes locales para aumentar sus ingresos durante la temporada veraniega. Así, se multiplicaron los hoteles familiares y las pensiones, así como el alquiler de viviendas habitadas por sus propietarios durante el invierno, $e$ incluso de habitaciones dentro del propio domicilio. En este sentido, para 1969, había en Mar del Plata 10.888 plazas hoteleras de entre $1^{\mathrm{a}}$ y $5^{\mathrm{a}}$ categoría, 1043 plazas en hoteles residenciales y 477 plazas en pensiones (Pastoriza, 2008). En ese contexto, la sola declaración de un testigo que afirmara haber visto a la trabajadora realizando tareas de limpieza (propias tanto de la mucama doméstica como de la de hotel) podía no resultar una prueba decisiva.

Si atendemos a los avisos clasificados del diario La Capital (diario local de mayor tirada en la ciudad de Mar del Plata) vemos que la "confusión" entre "mucamas" domésticas y de hotel también estaba presente en la demanda de trabajo. Los avisos que solicitaban empleadas para tareas de limpieza, ya fuera para hoteles o para casas de familia, hablaban de "servicio doméstico". Por otro lado, en ambos casos se observa una importante disparidad en la demanda de "mucamas" durante las distintas épocas del año, acompañando el carácter estacional de la actividad vinculada al turismo. "Mucama se necesita..." o "Muchacha para tareas de limpieza..." era la forma más común de 
convocar a las trabajadoras mediante los avisos clasificados; pocas veces se aclaraba si la empleada realizaría su trabajo en un hotel, una pensión o una vivienda particular.

Las trabajadoras eran convocadas a partir de las tareas que deberían realizar, no por el lugar en que lo harían. Esto podría indicar que, desde la perspectiva de los empleadores (y quizá también de las trabajadoras que respondían a estos avisos), el trabajo de las mucamas de hotel como el de las mucamas domésticas, era similar. Sin embargo, a la hora del otorgamiento de derechos y beneficios para las trabajadoras, las diferencias entre uno $y$ otro empleo eran claras, $y$ en esa diferencia se apoyaban las estrategias legales de quienes, confundiéndolas, buscaban algún beneficio. Para los empleadores, tanto en el ámbito de los avisos, como en el de la Justicia, la confusión no era gratuita. Lo que resulta sintomático es que, a pesar de lo sesgado de esta estrategia, en muchos de los casos los jueces terminaran aceptando dicha "confusión" como válida.

No fue así, sin embargo, en el caso de Mirta, que en 1959 reclamaba la suma de $12.448,30$ pesos $\mathrm{m} / \mathrm{n}$ en concepto de salarios y sueldo anual complementario por despido arbitrario de su trabajo como mucama de hotel, realizado entre el 23 de diciembre de 1957 y el 5 de febrero de 1958. Frente a esta demanda, su empleador sostuvo que ella se había desempeñado como "empleada doméstica" en tres departamentos aledaños al hotel, también de su propiedad. En este caso los jueces clasificaron a Mirta como una "mucama de hotel". Su decisión estuvo basada, esencialmente, en lo declarado por una testigo, que manifestó que la esposa del demandado le había dicho que necesitaba una "mucama de hotel", y que ella la había visto trabajando allí. ${ }^{17} \mathrm{En}$ el veredicto, el tribunal sostuvo que aún si sólo hubiera trabajado en los departamentos, la tarea de la trabajadora no hubiera podido ser clasificada como la de una empleada "doméstica", por

${ }^{17}$ Expediente 734, Tribunal de Trabajo No. 2, Mar del Plata, 1959. 
el beneficio económico que el empleador obtenía de los alquileres donde Mirta se desempeñaba. ${ }^{18}$

En un contexto propicio al resto de los trabajadores que iniciaban acciones legales (Cutuli, 2012), los fallos favorables a las mucamas (domésticas o de hotel), sin embargo, serían los menos. La feminización tanto del trabajo de mucamas de hotel como del servicio doméstico, sus similitudes con el trabajo doméstico no remunerado, y su escaso reconocimiento social condicionaban las decisiones de los jueces, redundando en una limitación de los derechos laborales de las trabajadoras.

En este sentido, el caso de María Celia resulta un buen ejemplo. Según lo expuesto oportunamente a la justicia, ella se había desempeñado como mucama en el hotel Petit Lamadrid, entre el 13 de noviembre de 1964 y el 15 de diciembre de 1965. Sin embargo, su empleador sostuvo que María Celia se había desempeñado en el ámbito familiar. El empleador poseía un edificio de dos plantas, en cuya planta baja -donde trabajaba María Celia- habitaba la familia, y en cuya planta superior había habitaciones alquiladas a personas que residían de forma permanente en el hotel. Los cuatro testigos que se presentaron en la causa sostuvieron que María Celia no había trabajado para los residentes del hotel, sino sólo para la familia de sus dueños, realizando tareas de cocina y limpieza. Basándose en ellos, los jueces determinaron que María Celia había trabajado como empleada doméstica y no como mucama de hotel, lo que implicó que frente a un reclamo de 105.135 pesos $\mathrm{m} / \mathrm{n}$, los jueces determinaran que sólo le correspondían 11.400 pesos $\mathrm{m} / \mathrm{n}$. En este caso observamos que la categoría profesional de la trabajadora (mucama doméstica o de hotel) era determinada tanto en función del espacio donde desarrollaba su actividad, como de la existencia (o no) de lucro por parte de la parte empleadora. ${ }^{19}$

La afiliación al sindicato fue otro de los criterios utilizados para determinar la categoría profesional de la demandante. En dos

18 Ídem.

${ }^{19}$ Expediente 5009, Tribunal de Trabajo No. 2, Mar del Plata, 1968. 
de las sentencias analizadas, con más de 14 años de diferencia entre una y otra, la no afiliación al sindicato gastronómico de las trabajadoras contribuyó a su identificación como domésticas. ${ }^{20} \mathrm{Si}$ repasamos brevemente la historia del sindicalismo en Argentina, observamos que después de 1946, bajo el gobierno de Perón, la afiliación sindical creció sustancialmente. La normativa sobre convenios colectivos, obras sociales, cuotas y aportes sindicales, contribuyó a incrementar los niveles de afiliación, que, de todos modos, mantuvieron tasas más bajas en el sector de comercio y servicios (Marshall, 2006). El peso de la participación sindical en la Argentina permite explicar que la afiliación al sindicato fuera un elemento considerado por los Tribunales Laborales a la hora de determinar la categoría profesional de la demandante.

Sin embargo, desde 1955 -con el Golpe de Estado conocido como "Revolución Libertadora"-, la Unión de Trabajadores Gastronómicos de la República Argentina perdió su personería gremial. Ésta le fue restituida 11 años después, en enero de 1966, por resolución del Ministerio de Trabajo y Previsión de la Nación. ${ }^{21}$ En ese mismo año se produjo un nuevo Golpe de Estado -la llamada "Revolución Argentina"-, cuyo gobierno ejerció una permanente presión sobre el sindicato. Estos vaivenes en la vida sindical, producto de la inestabilidad política del país, pueden haber influido también en la decisión de los trabajadores de afiliarse o no al sindicato correspondiente, lo que pone en duda la validez de este criterio para determinar la calidad de la relación laboral establecida entre la empleada y el empleador. ${ }^{22}$

Las confusiones se daban también en relación a las tareas desempeñadas. Una situación así se dio dentro del Hotel Nueva España. En su demanda, Estela sostenía que había trabajado en calidad de peona general a las órdenes de Celestino, en el hotel de

${ }^{20}$ Expediente $\mathrm{N}^{\circ}$ 989, Tribunal de Trabajo No. 2, Mar del Plata, 1960. Y Expediente $\mathrm{N}^{\circ}$ 10962, Tribunal de Trabajo No. 2, Mar del plata, 1974.

${ }^{21}$ Resolución del Ministerio de Trabajo y Previsión de la Nación No 13/66 del 14 de enero 1966.

${ }^{22}$ Por otro lado, si bien el Sindicato de Trabajadoras de Casas Particulares existía desde 1901, en este período no había una filial en la ciudad. 
su propiedad, entre el 20 de diciembre de 1964 y el 20 de marzo de 1965, fecha en que se retiró debido a la finalización de la temporada estival. Su demanda era por 75.500 pesos $\mathrm{m} / \mathrm{n}$ en concepto de sueldos no pagados y sueldo anual complementario. Sin embargo, según la declaración del demandando, Estela nunca se desempeñó allí, sino que había sido contratada por su hija Marina- para que trabajara en calidad de niñera al cuidado de sus dos hijas. El problema surgió a raíz de que durante los meses de la temporada 1964/1965, Marina se trasladó al hotel con toda su familia para ayudar en la administración de éste, llevando consigo a la niñera. El demandado aclaraba que ellos no vivían en el hotel, solamente trabajaban y comían allí. Al igual que en otros casos, apelando a los testimonios de los testigos convocados, que sostuvieron no haberla visto trabajando en el hotel, los jueces determinaron que la demandante no había logrado demostrar la existencia de una relación laboral con Celestino, el dueño del hotel. La demanda de Estela fue así desestimada en su totalidad. ${ }^{23}$

El llamado "régimen de invisibilidad" observado para las empleadas domésticas (Cutuli, 2012) se extendía a las mucamas de hotel, en una cadena que impedía la prueba de la relación laboral cuando ésta se desempeñaba en espacios de trabajo difíciles de catalogar o cuando implicaba la realización de tareas cercanas al trabajo doméstico no remunerado. La incidencia de las costumbres y del imaginario respecto de los roles de género -en particular la tradicional identificación de las tareas domésticas como responsabilidades femeninas "naturales"-, eran factores determinantes a la hora de definir el vínculo laboral entre trabajadoras y empleadores. Apelando a distintos argumentos, no sólo se discutían las categorías laborales de las trabajadoras sino que, incluso, se llegaba a negar la propia existencia de la relación laboral.

Esta estrategia no sólo se aplicaba en casos que involucraban la confusión entre mucamas domésticas y de hotel, sino también en otros casos en los que se negaba el carácter de

${ }^{23}$ Expediente $\mathrm{N}^{\circ}$ 5310, Tribunal de Trabajo No. 2, Mar del Plata, 1968. 
empleada doméstica a la trabajadora que iniciaba una demanda. Juan Carlos y Ana María, su esposa, se vieron involucrados en una situación como ésta. Ambos iniciaron un litigio contra su empleador, Adalberto, para quien habían desarrollado trabajos rurales: él, como encargado de establecimiento de campo, y ella, como cocinera de los peones. En su defensa, Adalberto negó tanto la categoría laboral de Juan Carlos, sosteniendo que sólo había trabajado para él de forma esporádica como peón general, y como el vínculo laboral con Ana María. Gracias a la información brindada por algunos testigos, casi todos ellos trabajadores de campos linderos, los jueces reconocieron la categoría laboral -y los derechos que derivaban de ella- que demandara Juan Carlos, aunque por un período menor al inicialmente reclamado. Con respecto a su esposa, los jueces determinaron que no se había desempeñado como cocinera. En este caso, observamos el peso de las costumbres en el veredicto de los jueces: mientras que el hecho de que los testigos hubiesen visto a Juan Carlos en el establecimiento rural implicaba una prueba suficiente de su relación laboral con el dueño del campo, la presencia de Ana María en el lugar de trabajo quedaba justificaba por el hecho de ser la esposa del encargado. Los trabajos que ella realizaba fueron tomados como trabajo doméstico no remunerado, tradicionalmente realizado por las mujeres de manera gratuita.

Los argumentos utilizados por los empleadores en su defensa frente a las demandas de las trabajadoras, muchas veces tomados también por los jueces para justificar su veredicto, dan cuenta de las formas en que se institucionalizaban los procesos de segregación ocupacional y de discriminación salarial que afectaban a las mujeres en el mercado de trabajo (García de Fanelli, 1989). Los casos en que se intentó confundir las categorías laborales de los varones trabajadores con la del servicio doméstico son prácticamente inexistentes, incluso cuando ellos también desarrollaran tareas de limpieza. De todas las sentencias dictadas por el Tribunal de Trabajo $\mathrm{n}^{\circ} 2$ entre los años 1958 y 1974, encontramos sólo un caso en que se intentó clasificar a un 
trabajador como empleado doméstico. ${ }^{24}$ Para el período aquí analizado, el servicio doméstico era una actividad "apropiada" sólo para mujeres. Su feminización se dio en un doble sentido: por un lado, la gran mayoría de quienes lo realizaban eran mujeres; por otro lado, las tareas desarrolladas estaban fuertemente asociadas con aquellas identificadas culturalmente como femeninas, en las que se expresaba la "naturaleza" de la mujer; trabajos relacionados a las tareas hogareñas (limpieza, cuidado, cocina, lavado, etc.) (Nari, 1998). Esta proximidad entre los trabajos y la asociación cultural y social que se daba entre las mujeres y las tareas domésticas, posibilitaban la confusión de ambos, constituyéndose en una estrategia utilizada en perjuicio de las mujeres trabajadoras.

\section{Consideraciones finales}

En la legislación argentina, las categorías profesionales de los trabajadores dependen tanto de las tareas realizadas como del lugar en que se realizan. En este sentido, las tareas de limpieza están incluidas en una diversidad de regímenes legales. En este artículo, hemos explorado dos casos que se incluyen bajo la categoría común de "mucama", pero se distinguen en relación al ámbito de desempeño: domésticas y de hotel. Esta distinción es de larga data: ya en 1944, las mucamas de hotel eran incluidas bajo el régimen de los trabajadores hoteleros y para 1955 serían parte del conjunto de los trabajadores gastronómicos, con derechos específicos establecidos en los sucesivos convenios colectivos que, entre otras cosas, incluían el laudo.

Las domésticas, por su parte, tuvieron que esperar a 1956 para la sanción del régimen legal. Tanto ese régimen como su exclusión explícita de los derechos garantizados por la Ley de Contrato de Trabajo de 1974, definieron una situación particularmente desventajosa para las trabajadoras de este sector, que perduró durante más de 50 años. La construcción de la

${ }^{24}$ Expediente $\mathrm{N}^{\circ}$ 6364, Tribunal de Trabajo No. 2, Mar del Plata, 1969. 
categoría "servicio doméstico" en la legislación supuso su separación respecto de actividades que hasta no mucho tiempo antes de la sanción del Decreto-Ley 326/56 formaban parte de él. La separación de trabajadores como los encargados de casas de rentas, los choferes particulares, o los trabajadores de limpieza de salas de espectáculos, oficinas y casas particulares, reforzó la feminización del sector. Supuso, además, la construcción de una jerarquía entre mujeres trabajadoras, que responde a un criterio androcéntrico de valoración del trabajo, donde el trabajo que se realiza en el mundo público y permite obtener un beneficio económico visible tiene mayor valor $\mathrm{y}$, por tanto, mayor reconocimiento en materia de derechos laborales.

Ahora bien, a pesar de esta separación en términos de la legislación, los usos de la ley revelan superposiciones entre las distintas categorías de "mucamas" que analizamos en este artículo. En el período analizado, mucamas de hotel y domésticas podían ser intencionalmente confundidas, lo que usualmente redundaba en un beneficio para el empleador. Como hemos visto, las condiciones que habilitaban esta superposición entre categorías profesionales con derechos tan desiguales estaban ancladas en situaciones particulares que, sin embargo, dan cuenta de representaciones más generales sobre el trabajo femenino y el trabajo doméstico (remunerado y no remunerado), que exceden esos casos puntuales y que dan cuenta del peso de las desigualdades de género en la (im)posibilidad de garantizar los derechos laborales de las mujeres trabajadoras.

En un escenario de crecimiento del turismo masivo, en el que en la ciudad de Mar del Plata la oferta de servicios de alojamiento para turistas se había multiplicado y diversificado, el lugar de trabajo de las "encargadas de la limpieza" podía ser difícilmente catalogable: ¿hotel, hostería, pensión, espacio doméstico? La posibilidad del empleador de obtener una ganancia a partir de ese trabajo o la afiliación de la trabajadora a un sindicato específico podían ser elementos definitorios, siempre que pudieran probarse. Por otra parte, las actividades de trabajo realizadas, aún cuando fueran descriptas por un testigo, podían 
fácilmente asimilarse a las de una empleada doméstica o, incluso, a las de un ama de casa. Se producía así un desplazamiento de la invisibilidad (en términos de derechos): del trabajo doméstico no remunerado, al servicio doméstico, y de allí a las empleadas de hotel. Dicho desplazamiento se apoyaba en la cercanía de las actividades desarrolladas tanto como en la condición de mujeres de quienes las realizaban.

El acceso a la justicia, por otra parte, revela la articulación de profundas desigualdades de género y clase. Desde el inicio de la relación laboral, los empleadores - en su mayoría varones - se encontraban en una mejor situación respecto del conocimiento de la ley que las trabajadoras. En la instancia judicial, esta desigualdad se veía reforzada por el hecho de que las instituciones y los operadores de justicia seguían una lógica androcéntrica en la aplicación de la ley. Qué constituía "trabajo", qué demostraba la existencia de una relación laboral, qué probaba la categoría de la trabajadora, eran cuestiones evaluadas a partir de criterios construidos en torno de un modelo de trabajador masculino. Como consecuencia de la aplicación de dichos criterios, los derechos laborales de las mujeres trabajadoras resultaban más vulnerables que los de los varones.

La historia de la legislación laboral y de los usos de la ley permite reconstruir representaciones sobre el trabajo de las "mucamas", tanto de hotel como domésticas, de su distinción y de sus recurrentes superposiciones. Revelan, en última instancia que, aún décadas después de la emergencia de regímenes legales específicos, existían canales de comunicación entre unas y otras, asentados en su cercanía con el trabajo doméstico y en la identificación de éste último como un trabajo femenino que las mujeres usualmente realizaban para sus familias de modo gratuito. $\mathrm{Si}$ en Argentina, las décadas centrales del siglo XX fueron testigo de la emergencia de unos senderos que se bifurcaban para mucamas de distinto tipo, fueron también un escenario propicio para su confusión y superposición, que tuvieron como resultado un complejo sistema de desigualdades en el mundo del trabajo y de la justicia. 


\section{Fuentes consultadas}

Censo General de Población de 1960, Instituto Nacional de Estadística y Censos.

III Censo General de Población, Dirección Nacional de Estadística y Censos, 1914.

IV Censo General de Población, Dirección Nacional de Estadística y Censos, 1947.

Convenio Colectivo de Trabajo para la Industria Gastronómica y Hotelera, zona atlántica. Vigente entre el $1^{\circ}$ de mayo de 1956 y el 30 de abril de 1958.

Decreto Ley 326/1956.

Decreto Ley 24.348/1957

Decreto Ley 7474/1956

Decreto Ley 22310

Diario La Capital de Mar del Plata.

Diarios de Sesiones, Cámara de Diputados del Congreso de la Nación, disponibles en la Biblioteca del Congreso de la Nación.

Diarios de Sesiones, Cámara de Senadores del Congreso de la Nación, disponibles en la Biblioteca del Congreso de la Nación.

Encuestas de empleo y desempleo, Buenos Aires, julio de 1963 y abril de 1964, Instituto Nacional de Estadística y Censos, Buenos Aires, 1964. Ley 12.921.

Ley de Contrato de Trabajo.

Registros de Sentencias, Tribunal de Trabajo No. II de Mar del Plata, archivo del propio tribunal.

Resolución $N^{\circ} 49 / 49$ de la Secretaría de Trabajo y Previsión de la Nación.

Resolución № 160/55 del Ministerio de Trabajo y Previsión de la Nación. Resolución del Ministerio de Trabajo y Previsión de la Nación No 13/66 del 14 de enero 1966.

Revista Derecho del Trabajo.

\section{Referencias bibliográficas}

ALLEMANDI, Cecilia. Una aproximación a las transformaciones económicas y ocupacionales en la ciudad de Buenos Aires y a las precariedades del torbellino modernizador, 1869-1914. Jornadas de Jóvenes Investigadores, Instituto de Investigaciones Gino Germani, Buenos Aires, 4 al 6 de noviembre 2009, pp.1-20. 
BlOFIELD, Merkie. Feudal Enclaves and Political Reforms: Domestic Workers in Latin America. Latin American Research Review, vol. 44, $\mathrm{n}^{\circ}$ 1, Pittsburgh, Pittsburgh University Press, 2009, pp.158-190.

BLuM, Ann. Speaking of Work and Family: Reciprocity, Child Labor, and Social Reproduction, Mexico City, 1920-1940. Hispanic American Historical Review, vol. 91, $\mathrm{n}^{\circ}$ 1, Durham, Duke University Press, 2011, pp.63-95.

BORDERÍAS, Cristina, Cristina Carrasco y Carmen Alemany (comp.). Las mujeres y el trabajo. Rupturas conceptuales. Madrid, Economía Crítica, 1994.

CuTULI, Romina. Desigualdades en el acceso a la justicia: un "régimen de invisibilidad". El servicio doméstico en la provincia de Buenos Aires (1990-2010). Primer Congreso Latinoamericano de Historia de las Mujeres, Buenos Aires, 20 y 21 de septiembre 2012, pp.1-17.

Devali, Mario. Derecho del trabajo. Revista crítica mensual de jurisprudencia, doctrina y legislación (1956-1965). Buenos Aires, La Ley, 1967.

FESCINA, Andrés. Régimen jurídico del servicio doméstico y su reglamentación. Tesis (Doctorado), Derecho y Ciencias Sociales, Universidad de Buenos Aires, 1956.

GARCía DE FANELli, Ana. Patrones de desigualdad social en la sociedad moderna: una revisión de la literatura sobre discriminación ocupacional y salarial por género. Desarrollo Económico, vol. 29, $\mathrm{n}^{\circ}$ 114, Buenos Aires, 1989, pp.239-264.

GRINBERG, Oscar. El servicio doméstico en el derecho argentino. Tesis de Doctorado. Derecho y Ciencias Sociales, Buenos Aires, 1951.

HUTCHISON, Elizabeth. Labors Appropriate to their sex. Gender, Labor and Politics in Urban Chile, 1900-1930. Durham y Londres, Duke University Press, 2001.

HuTCHISON, Elizabeth. Shifting Solidarities: The Politics of Household Workers in Cold War Chile. Hispanic American Historical Review, vol. 91, n 1, Durham, Duke University Press, 2011, pp.129-162.

JAMES, Daniel and FRENCH, John D. The Gendered Worlds of Latin American Women Workers. Durham and London, Duke University Press, 1997. 
KROTOSCHIN, Ernesto y Ratti, Jorge. Código del Trabajo Comentado y Concordado. Buenos Aires, Ed.Depalma, 1967.

LoBATO, Mirta. Historia de las Trabajadoras en la Argentina (1869-1960). Buenos Aires, Edhasa, 2007.

MARSHALl, Adriana. Efectos de las regulaciones del trabajo sobre la afiliación sindical: Estudio comparativo de Argentina, Chile y México. Cuadernos del IDES, n 8, Buenos Aires, Abril 2006, pp.3-31.

NARI, Marcela. De la maldición al derecho. Notas sobre las mujeres en el mercado de trabajo. Buenos Aires, 1890-1940. En: GARRIDO, H. y Bravo, M. C. (coord.). IV Jornadas de Historia de las Mujeres y Estudios del Género. Tucumán, Universidad Nacional de Tucumán, 1998, pp.139-155.

NARI, Marcela. Políticas de maternidad y maternalismo político. Buenos Aires, Biblos, 2004.

NAZAR, Mariana. Introducción al reservorio documental "Tribunal de Servicio Doméstico". Archivo General de la Nación. (mimeo)

OLCOTT, Jocelyn. Introduction: Researching and Rethinking the Labours of Love. Hispanic American Historical Review, vol. 91, n 1, Durham, Duke University Press, 2011, pp.1-27.

PASTORIZA, Elisa. Estado, gremios y hoteles. Mar del Plata y el peronismo. Estudios sociales, n ${ }^{\circ} 34$, Santa Fe, primer semestre 2008, pp.121-147.

PITE, Rebekah, Entertaining Inequalities. Hispanic American Historical Review, vol. 91, $\mathrm{n}^{\circ}$ 1, Durham, Duke University Press, 2011, pp.97-128.

RoJAS, Julio. El servicio doméstico. Régimen Jurídico. Tesis (doctorado), Derecho y Ciencias Sociales, Universidad de Buenos Aires, 1956.

RosemblatT, Karin. Gendered Compromises. Political Cultures and the State in Chile, 1920-1950. Chapell Hill, The University of North Carolina Press, 2000.

SARTI, Raffaella. Domestic Service since 1750. Gender \& History, vol. 18, $n^{\circ} 2,2006$.

SCOTT, Joan W. El género: una categoría útil para el análisis histórico. En: NAVARRO, Marysa y StimPSON, Catherine (comp.). Sexualidad, 
género y roles sexuales. Buenos Aires, Fondo de Cultura Económica, 1990 [1986].

SCOTT, Joan W. The evidence of experience. Critical Inquiry, vol. 17, $\mathrm{n}^{\circ} 4,1991$.

SteEdman, Carolyn. Labours Lost. Domestic Service and the Making of the Modern England. Cambridge, Cambridge University Press, 2009.

THOMPSON, Edward Palmer .Los orígenes de la ley negra. Un episodio de la historia criminal inglesa. Buenos Aires, Siglo XXI, 2010 [1975].

TizziANI, Ania. El Estatuto del Servicio Doméstico y sus antecedentes: las huellas de un debate inconcluso. Congreso Iberoamericano de Historia de las Mujeres, Buenos Aires, 20 y 21 de septiembre 2012, pp.1-14.

VÁZQUEZ Lorda, Lilia. El otro ángel del hogar es mujer, trabajadora y asalariada. Las empleadas domésticas y el catolicismo en la Argentina de los años 1950. En ÁlvareZ, Norberto (comp.). Familia, género y después... Itinerarios entre lo público, lo privado y lo íntimo. Rosario, Prohistoria, 2010, pp.107-126.

WAJCMAN, Judy. El género en el trabajo. En: LAUFER, Jacqueline; MARRY, Catherine y MARUANI, Margaret (eds.). El trabajo del género. Las ciencias sociales ante el reto de las diferencias de sexo. Valencia, Germania, 2005.

WeInsteIn, Barbara. For Social Peace in Brazil. Industrialists and the Remaking of Working Class in Sao Paulo, 1920-1964. Chapel Hill and London, The University of North Carolina Press, 1996.

ZELIZER, Viviana. La negociación de la intimidad. Buenos Aires, FCE, 2009. 